\title{
An Investigation of Cold-Season Short-Wave Troughs in the Great Lakes Region and Their Concurrence with Lake-Effect Clouds
}

\author{
NiCHOLAS D. METZ \\ Department of Geoscience, Hobart and William Smith Colleges, Geneva, New York \\ ZACHARY S. BRUICK \\ Department of Atmospheric Science, Colorado State University, Fort Collins, Colorado \\ PEYTON K. CAPUTE \\ Department of Atmospheric and Environmental Sciences, University at Albany, State University \\ of New York, Albany, New York \\ Molly M. Neureuter AND Emily W. OTT \\ Department of Geoscience, Hobart and William Smith Colleges, Geneva, New York \\ MiCHAEL F. SESSA \\ Department of Atmospheric Sciences, University of Illinois at Urbana-Champaign, Urbana, Illinois
}

(Manuscript received 19 July 2018, in final form 16 January 2019)

\begin{abstract}
The downwind shores of the Laurentian Great Lakes region often receive prolific amounts of lake-effect snowfall during the cold season (October-March). The location and intensity of this snowfall can be influenced by upper-tropospheric features such as short-wave troughs. A 7-yr cold-season climatology of 500-hPa short-wave troughs was developed for the Great Lakes region. A total of 607 short-wave troughs were identified, with an average of approximately 87 short waves per cold season. Five classes of short-wave troughs were identified on the basis of their movement through the Great Lakes region. This short-wave trough dataset was subsequently compared with the lake-effect cloud-band climatology created by N. F. Laird et al. in 2017 to determine how frequently short-wave troughs occurred concurrently with lake-effect cloud bands. Of the 607 short-wave troughs identified, 380 were concurrent with lake-effect clouds. Over $65 \%$ of these 380 short-wave troughs occurred with a lake-effect cloud band on at least four of the five Great Lakes. Short-wave troughs that rotated around the base of a long-wave trough were found to have the highest frequency of concurrence. In general, concurrence was most likely during the middle cold-season months. Further, Lake Michigan featured the highest number of concurrent events, and Lake Erie featured the fewest. It is evident that short-wave troughs are a ubiquitous feature near the Great Lakes during the cold season and have the potential to impart substantial impacts on lake-effect snowbands.
\end{abstract}

\section{Introduction}

Lake-effect snow is a common occurrence during the cold season in the North American Laurentian Great Lakes region (Fig. 1) and can be a significant hazard to society, particularly in terms of travel disruption, property damage, and increased injuries and fatalities

Corresponding author: Nicholas D. Metz,nmetz@hws.edu (e.g., Schmidlin 1993; Kunkel et al. 2002; Call 2005). Conversely, this sometimes intense snowfall can be an economic benefit to some sectors of the local economy such as ski resorts (e.g., Schmidlin 1993; Kunkel et al. 2002). Lake-effect snow forms as cold polar air passes over the relatively warm lake water during the late fall and winter months, producing extreme instability. This instability can contribute to prolific snowfall amounts that accumulate along the downwind shore 


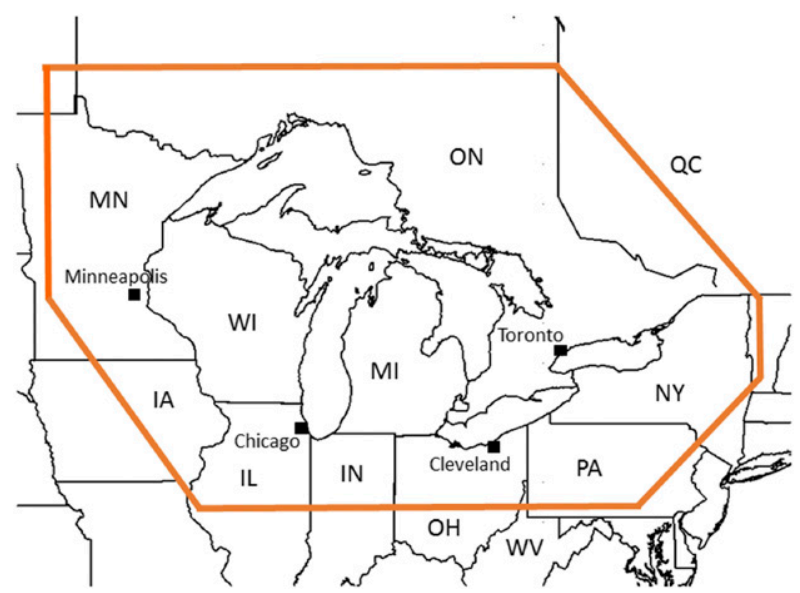

FIG. 1. A polygon that illustrates the Great Lakes region that is considered in this study.

of the lakes (e.g., Niziol et al. 1995; Laird et al. 2017; Kristovich et al. 2017).

Niziol et al. (1995) offers a classification for five types of lake-effect snowbands. This classification includes shore parallel bands associated with strong winds along the long axis of the lake (type I), wind parallel rolls perpendicular to the long axis of the lake (type II), laketo-lake connection bands (type III), shore parallel bands attributable to a land-breeze interaction (type IV), and mesoscale vortices (type V). A number of predictor variables have been found to be important to the production of lake-effect snow. For example, a temperature difference between the lake and $850 \mathrm{hPa}$ of at least $13^{\circ} \mathrm{C}$ produces an unstable lapse rate that allows for lake-effect convection to form (e.g., Niziol et al. 1995; Baijnath-Rodino et al. 2018). As this temperature difference increases, lake-effect snow has the potential to increase in intensity. The direction of the steering wind is important in determining the fetch of air parcels over the lake and the associated residence time of these parcels. As fetch increases, the vertical temperature gradient can increase as well, resulting in more instability (Baijnath-Rodino et al. 2018). Furthermore, an increase in vertical wind shear in the boundary layer tends to cause lake-effect bands to become less organized and snowfall impacts can be lessened (e.g., Niziol et al. 1995). Last, low-level convergence has the potential to increase the intensity of lake-effect bands (e.g., Niziol et al. 1995). Since lake-effect snow is usually thought of as a lower-tropospheric phenomenon, less focus is typically given to upper-level features, such as short-wave troughs.

Short-wave troughs are upper-level progressive waves that feature cyclonic circulation and move in the same general direction as the upper-level flow (American
Meteorology Society 2018). Differential cyclonic vorticity advection (CVA) found ahead of short-wave troughs provides forcing for ascent and can lead to atmospheric destabilization (e.g., Jiusto et al. 1970; Niziol et al. 1995; Lackmann 2001; Holton and Hakim 2013). For example, the passage of a short-wave trough and its attendant CVA over a lake-effect snowband can lead to deepening of the lake-induced boundary layer, first through an increase in upward vertical motion and then followed by cooling temperatures aloft (Jiusto et al. 1970; Niziol et al. 1995). With an increase in the height of the capping inversion, deeper convection over the lake can cause larger snowfall totals than initially expected (Niziol et al. 1995). Niziol et al. (1995) describes a case study where a vorticity maximum, in association with an upper-level trough centered over Lake Erie, produced considerable CVA that led to further development of a lake-effect band over Lake Ontario. After the passage of the trough, vertical motion diminished and the lake-effect band dissipated. A short-wave trough can also provide the support needed for lake-effect bands to impact areas inland from a lake shore (Niziol et al. 1995) and may cause subtle changes in band orientation. While short-wave troughs reside in the middle and upper levels of the atmosphere, they have important consequences for weather at the surface, often contributing to cyclogenesis (e.g., Petterssen 1955; Petterssen and Smebye 1971; Harman et al. 1980; Kocin et al. 1995).

Sanders (1988) published a climatology of troughs in the Northern Hemisphere by conducting a subjective analysis of the 552-dam contour at the 500 -hPa pressure level. Trough development was favored in areas of high terrain, such as the Rocky Mountains, while dissipation was favored over the eastern Atlantic Ocean (Sanders 1988). Further, Lefevre and Nielsen-Gammon (1995) conducted an objective analysis of troughs in the Northern Hemisphere and found that troughs tend to have preferred pathways, often following cyclonic storm tracks over northern continents, such as North America. Thus, short-wave troughs can and often do track directly over the Great Lakes region.

Lake-effect snow throughout the Great Lakes region is known to create operational forecast problems for meteorologists because tiny fluctuations in environmental conditions (e.g., subtle changes in the ambient wind direction) can impart drastic impacts on lake-effect snowbands. The interaction of short-wave troughs with lake-effect snow can further complicate forecasting as each trough has the ability to change the intensity and location of preexisting lake-effect snowbands. Given this potential forecasting issue, it is important to understand how frequently short-wave troughs pass over a Great Lake coincident with an ongoing lake-effect 
cloud band. This information can potentially help meteorologists refine their lake-effect forecasts during the cold season. Thus, the purpose of this study is to document a 7-yr cold-season climatology of short-wave troughs in the Great Lakes region and identify how frequently these troughs occur concurrently with a lake-effect cloud band. In particular, this work will utilize a lake-effect cloudband climatology developed by Laird et al. (2017). The remainder of this paper is organized as follows. Section 2 will document the method used to identify short-wave troughs and lake-effect cloud bands. Section 3 will discuss the results of a 7-yr climatology of Great Lakes shortwave troughs, and section 4 will show how frequently these troughs occur in conjunction with lake-effect bands in the Great Lakes region. Section 5 will summarize pertinent results in the context of previous research and discuss important forecasting implications.

\section{Method}

\section{a. Short-wave trough climatology}

A semiobjective analysis of short-wave trough passages over the Great Lakes region (Fig. 1) was conducted for seven cold seasons (October-March) spanning 2007/08 through 2013/14 using the 20-km-horizontal-resolution Rapid Update Cycle (RUC) or Rapid Refresh (RAP) analyses (https://www.ncdc.noaa.gov/data-access/model-data/ model-datasets/rapid-refresh-rap; Benjamin et al. 2004, 2016) (approximately $2 \%$ of the data were unavailable). The RAP model is an updated version of the RUC and was put into use on 1 May 2012. Both models feature 50 vertical levels over the North American region. These RUC/RAP analysis grids are often used to diagnose observed synoptic and mesoscale phenomena such as short-wave troughs (e.g., Market et al. 2003; James and Johnson 2010; Metz and Bosart 2010; Kumjian and Lombardo 2017). These years were chosen for analysis because before 2007/08 the data availability was somewhat sparser and the lake-effect cloud climatology with which these troughs were compared only extends through 2013/14 (see later in section 2). Even with only considering seven cold seasons, more than 600 short-wave troughs were identified and cataloged (see section 3). The definition of the Great Lakes region can be vague and has varied greatly in the literature. For this investigation, studies done by Petterssen and Calabrese (1959), Bates et al. (1995), Cortinas (2000), and Payer et al. (2011) were utilized to create the polygon that comprises the Great Lakes region considered herein (Fig. 1).

The following three criteria had to be present for six consecutive hours (three consecutive 3-hourly RUC/RAP analyses) within the Great Lakes region for a short-wave trough to be identified: 1 ) visible cyclonic curvature in the 500-hPa wind and height fields, 2) a 500-hPa vorticity maximum of at least $18 \times 10^{-5} \mathrm{~s}^{-1}$ within the curvature, and 3 ) a curvature width (satisfied by both $500-\mathrm{hPa}$ wind and height fields) that does not exceed $1500 \mathrm{~km}$ [in line with the definition of short-wave trough size in Tuttle and Davis (2013)]. If a short-wave trough lost any of these characteristics while in the Great Lakes region, its tracking was discontinued. The 6-h period was chosen so as to identify coherent features. However, the results presented herein do not change in a substantial fashion if this number is reduced to $3 \mathrm{~h}$ or increased to $9 \mathrm{~h}$. A start time was recorded when a short wave and its associated vorticity maximum entered or formed in the Great Lakes region, and an end time was noted when the short wave and vorticity maximum exited or dissipated in the region. The short-wave trough duration was calculated, and the direction of movement was also noted using the location where the center of the trough axis intersected the vorticity maximum. After reviewing data from several years, short-wave troughs were binned into five categories that are based primarily on the direction of movement. These five classes were type $\mathrm{W}$ [movement from the west (between $247.5^{\circ}$ and $292.5^{\circ}$ )], type NW [movement from the northwest (between $292.5^{\circ}$ and $337.5^{\circ}$ )], type SW [movement from the southwest (between 202.5 and $\left.247.5^{\circ}\right)$ ], type LWT [movement rounding the base of a long-wave trough (changing motion direction throughout its life cycle in the Great Lakes region)], and type COL (cutoff lows). While cutoff lows are not typically classified as short-wave troughs, a few of these lows met the classification criteria and thus received their own category. The choice was made to group the troughs on the basis of direction of motion because these different directions of motion likely correlate to different environmental scenarios that could impact the frequency of lake-effect clouds (see next section). For example, flow out of the northwest is likely much colder and more likely to result in lake-effect cloud bands than is flow out of the southwest. Further, all but two of the short-wave troughs in the 7-yr climatology fit in one of the five categories described above.

Where appropriate, statistical testing was conducted on results related to the differing short-wave trough types using the ANOVA test (Wilks 2006). In particular, the Welch ANOVA test was chosen for use because it does not require the assumption of variance homogeneity (Zar 2009). The ANOVA results are reported in the following manner: [Welch's $F(\mathrm{df} 1, \mathrm{df} 2)=F, p$ ], where df1 is the degrees of freedom between groups, df2 is the degrees of freedom within groups, $F$ is the test 
statistic calculated by the Welch ANOVA, and $p$ is the $p$ value. The Welch ANOVA adjusts the degrees of freedom since equality of variance is not assumed, and thus it is possible for the degrees of freedom to have decimal values.

\section{b. Short-wave troughs and lake-effect clouds}

To determine the concurrence of short-wave troughs and lake-effect cloud bands, the short-wave trough dataset spanning the cold seasons of 2007/08 through 2013/14 was compared with the lake-effect cloud-band climatology for the same seasons as documented by Laird et al. (2017). This lake-effect climatology extends for the cold seasons (October-March) from 1997/98 through 2013/14. For this study, only the last seven years of the climatology were utilized. Since this lakeeffect cloud-band climatology utilizes GOES visible satellite imagery extracted over the Great Lakes region, only daytime cloud bands were recorded. The visible satellite imagery was available in approximately 15-min intervals. The climatology of lake-effect clouds may have been somewhat of an underestimate because the visible satellite imagery only captured lake-effect cloud bands during the day. However, previous studies have found a maximum in lake-effect precipitation frequency during the morning hours (e.g., Kristovich and Spinar 2005).

If a lake-effect cloud band was present over or extending from a lake on the same day as a short-wave trough was passing over the lake, the occurrence was documented as a concurrent event. A short-wave trough could occur concurrently with a lake-effect band on more than one lake. When determining the concurrence of short-wave troughs and lake-effect clouds, the cutofftype troughs from the climatology (type COL) were not considered because of their distinctly different structure and their long-lasting nature.

\section{Results}

\section{a. Frequencies by type of short-wave trough}

A total of 607 cold-season short-wave troughs occurred in the Great Lakes region spanning 2007/ 08-2013/14. A closer examination of the yearly statistics shows that type-W short waves were the most frequent with a mean of 29.3 per cold season (Fig. 2). This result is expected given the predominant westerly flow across the Great Lakes region associated with the typical upper-level jet streamflow direction. The second most frequent class was type LWT with a mean of 22.9 short waves (Fig. 2). Multiple type-LWT short-wave troughs tend to occur in rapid succession and follow each other around a single long-wave trough (not shown). Since short-wave troughs can change the orientation of lake-effect snowbands (e.g., Niziol et al. 1995), these type-LWT troughs have the potential to cause a large impact on any preexisting bands given their changing direction of motion. Type-NW short waves were also common over the study period with a mean of 20.9 per cold season (Fig. 2). These type-NW troughs typically drop quickly out of Canada and are often associated with Alberta clippers that tend to travel across the central Great Lakes toward the mid-Atlantic states bringing cold weather that is often conducive for lakeeffect snow. Type-NW troughs often feature a positive tilt (not shown). Type-SW and type-COL short waves were not as frequent in the Great Lakes region with yearly cold-season means of 10.1 and 3.6, respectively (Fig. 2). Southwest flow across the Great Lakes region was not as common during the cold seasons in this 7-yr climatology, and cutoff lows often exceed the curvature width criterion for classification and are thus not typically considered herein. These differences in the number of short-wave troughs of each type per cold season are significant using ANOVA testing [Welch's $F(4,13.85)=29.41, p<0.001]$.

\section{b. Seasonal frequencies}

Short-wave trough passage was most frequent during the 2013/14 season, when 116 progressed through the Great Lakes region (Fig. 3). The 2013/14 season featured 26 more short-wave trough passages than the second highest year, indicating that 2013/14 was an anomalous cold season. This active year for short waves was correlated with record-breaking snowfall for several states in the Great Lakes region and extensive ice cover on the Great Lakes (http://www.ncdc.noaa.gov/sotc/ national/201402). This larger snowfall could be at least in part due to the potential for short-wave troughs to intensify lake-effect snowbands (e.g., Niziol et al. 1995). The least active cold season was 2008/09 with 74 shortwave trough passages (Fig. 3). The other years in the climatology featured 81-90 short-wave trough passages through the Great Lakes region (an average of a shortwave trough approximately every other day). While most years featured a similar number of short-wave trough passages through the Great Lakes region, there can be interannual variability of almost $50 \%$, suggesting the potential for a wide variation of lake-effect snow modulation from season to season.

\section{c. Monthly frequencies}

The total number of short-wave troughs gradually increased as the cold season progresses from October to 


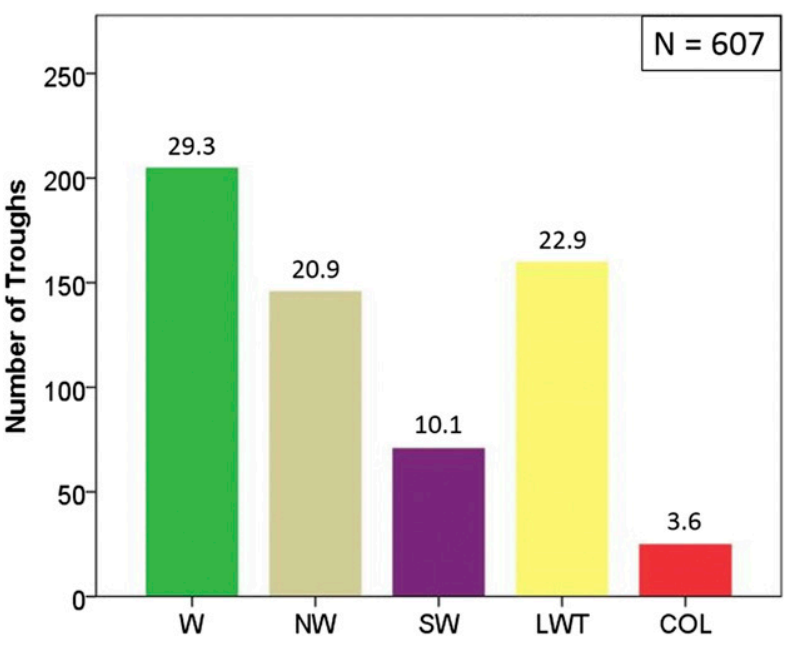

FIG. 2. The total number of each cold-season short-wave trough type identified during the cold seasons of 2007/08-2013/14. The mean number of short-wave troughs for a year is labeled above each bar. The types are defined in section $2 \mathrm{a}$.

December and then decreased into March (Fig. 4). For most months, type-LWT troughs were the most frequent type of short-wave trough. This is particularly true in January and February when type-LWT short-wave troughs occur an average of 5.1 and 5.0 times per month, respectively (Fig. 4). Type-LWT troughs often occur as a broad trough sets up across the eastern United States with the short-wave troughs rotating through the longerwave trough. During November and March, type-W troughs were the most common with averages of 5.4 and 5.0 per month, respectively. Type-SW troughs occurred most frequently in December (average of 2.6 per month), with slightly smaller numbers in October and November. Type-NW troughs also reached their highest frequency in December (average of 5.1 per month). Type COL was the least frequent short-wave trough type in every month but attain their maximum in October with an average of 1.1 each year (Fig. 4). Differences in the monthly frequencies of each short-wave trough type are not significant using ANOVA testing. However, it is clear from the seven years included in this study that certain portions of the cold season are more favorable to different types of short-wave troughs in the Great Lakes region.

\section{d. Duration}

The median duration for all short-wave troughs in the Great Lakes region was $24 \mathrm{~h}$. Only 12 of these shortwave troughs existed for the minimum of $6 \mathrm{~h}$ in the Great Lakes region. Thus, once a short-wave trough enters the Great Lakes region, it has the potential to cause impacts for a substantial period of time. The longest duration for a short wave in the Great Lakes region

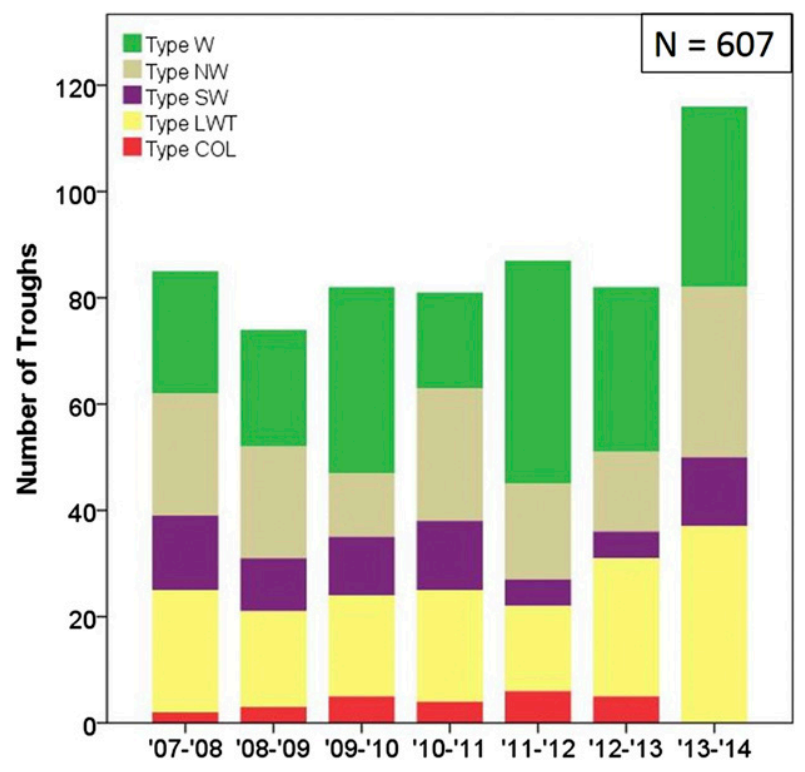

FIG. 3. The total number of cold-season short-wave troughs during each year stacked by type.

was $123 \mathrm{~h}$ for a type-COL trough. The duration for eight short-wave troughs could not be determined because of missing data.

Short-wave troughs in January and February had median durations in the Great Lakes region of $24 \mathrm{~h}$ (Fig. 5a). Short-wave troughs in November and December had a slightly shorter median duration of $21 \mathrm{~h}$. Conversely, October and March short-wave troughs had a 3-h-longer median duration of $27 \mathrm{~h}$ (Fig. 5a). The October value is influenced by type-COL short waves since October featured the most of these troughs (Fig. 4) and these spend the longest time in the Great Lakes region with a median duration of $54 \mathrm{~h}$ (Fig. 5b). Differences in short-wave trough duration by month are significant using ANOVA testing [Welch's $F(5,271.67)=3.12, p=0.01$ ]

While type-COL short-wave troughs existed within the Great Lakes region for the longest duration, types W and NW had a median duration of $24 \mathrm{~h}$ in the Great Lakes region. Type-SW short waves dissipated or left the defined region more quickly and had a median duration of $21 \mathrm{~h}$, as these short waves tended to traverse a slightly smaller portion of the region than other types of troughs given that the Great Lakes region considered herein is elongated along an axis from west-northwest to east-southeast (Figs. 1 and 5b). Type-LWT troughs had a slightly longer median duration of $27 \mathrm{~h}$ in the Great Lakes region as these troughs changed movement direction allowing them to stay in the defined region for a longer period of time. Differences in short-wave trough duration by type are significant using ANOVA testing [Welch's $F(4,126.00)=5.33, p=0.001$ ]. 


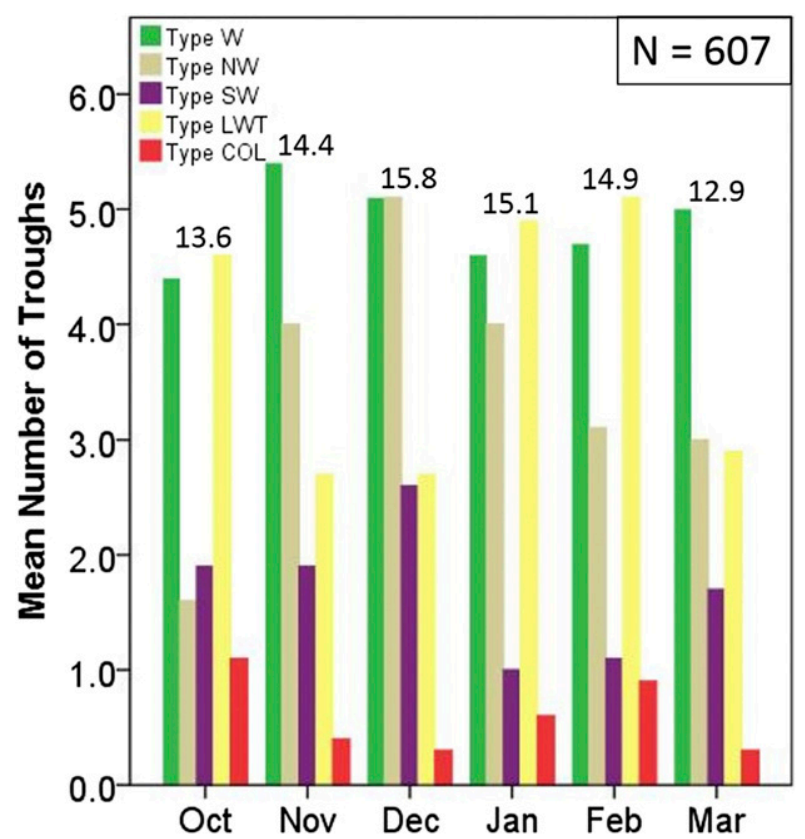

FIG. 4. The mean number of cold-season short-wave trough types for each month. The mean number of total short-wave troughs for each month is listed above each cluster.

\section{e. Short-wave troughs concurrent with lake-effect cloud bands}

As mentioned in section 2, only the non-type-COL short-wave troughs are considered when examining how often a short-wave trough occurs concurrently with a lake-effect cloud band. Of the 582 short-wave troughs identified in the climatology that were not type COL, a total of 380 troughs were concurrent with lake-effect cloud bands on at least one of the five Great Lakes. The most frequent type of short-wave trough concurrent with lake-effect cloud bands is type W with 125 troughs, followed closely behind by type LWT with 117 troughs (Fig. 6a). While type W only had a $61.0 \%$ concurrence with lake-effect cloud bands, $73.1 \%$ of type-LWT troughs were concurrent, the highest percentage associated with lake-effect clouds of any type. Type SW had the least frequent association with lakeeffect cloud bands with 31 concurrent events, a $43.7 \%$ frequency (Fig. 6a). This smaller frequency is not surprising given that flow with a component from the south is often somewhat warmer and less likely to allow for lake-effect cloudiness.

The monthly distribution of short-wave troughs concurrent with lake-effect cloud bands increased from 55 in October to a maximum of 81 in December, then decreased to a minimum of 41 in March (Fig. 6b). December and January featured the highest percentage of troughs concurrent with lake-effect cloud bands at
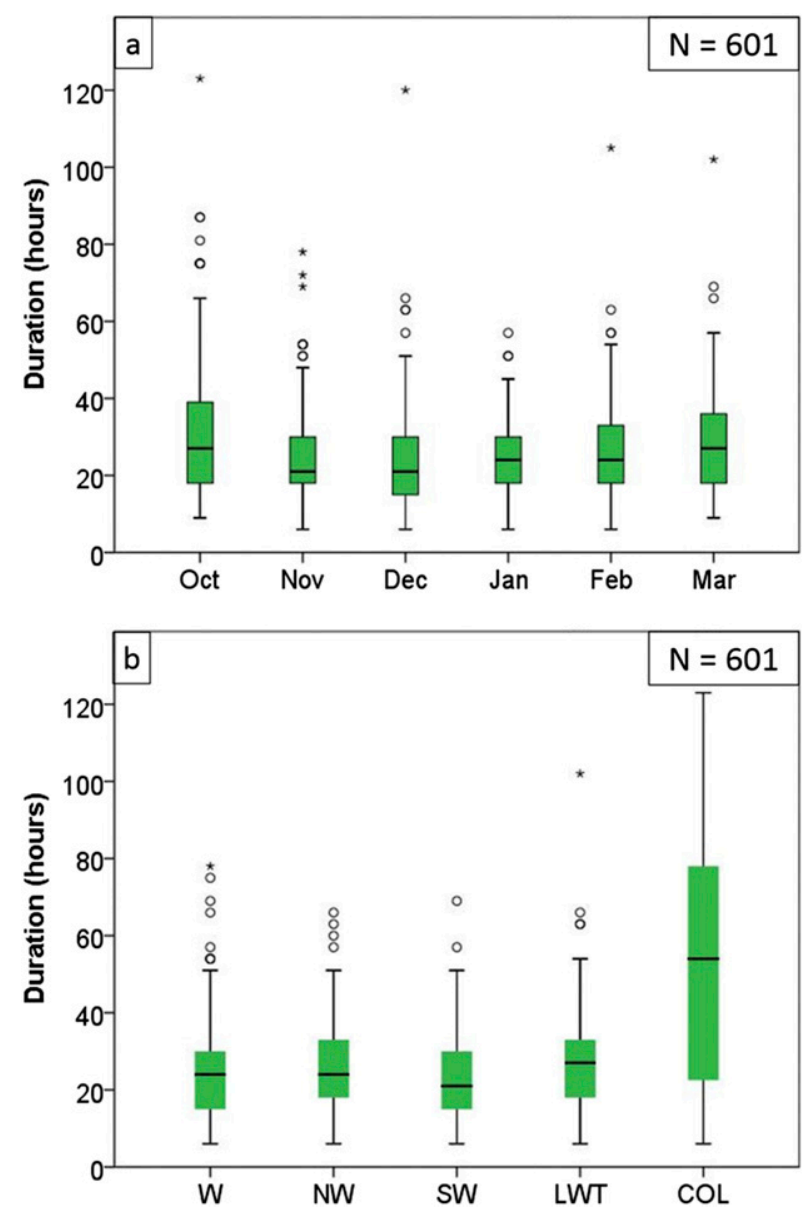

FIG. 5. (a) The duration (hours) of cold-season short-wave troughs during each month in the Great Lakes region, and (b) the duration of each type of short-wave trough in the Great Lakes region. The green shading inside the box represents the interquartile range, the whiskers represent the two outer quartiles, and the black line represents the median. The open circles indicate outlier values, and the stars show extreme outlier values.

$74.3 \%$ and $77.2 \%$, respectively (Fig. 6b). During these two months, cold air is often present along with lake waters that are still warm enough to produce lake-effect cloud bands. March had the highest number of troughs with no connection to a lake-effect cloud band likely because ambient atmospheric temperatures often warm in March, while at the same time lake ice remains on a number of the Great Lakes, inhibiting lake-effect potential.

Out of the 380 short-wave troughs that were concurrent with lake-effect cloud bands, $65 \%$ were concurrent on at least four of the five Great Lakes (Fig. 7). All shortwave troughs that lasted longer than $48 \mathrm{~h}$ were concurrent with lake-effect clouds on at least three of the Great Lakes (not shown). Thus, short-wave troughs potentially have a widespread impact on lake-effect clouds and precipitation over the Great Lakes region. The 

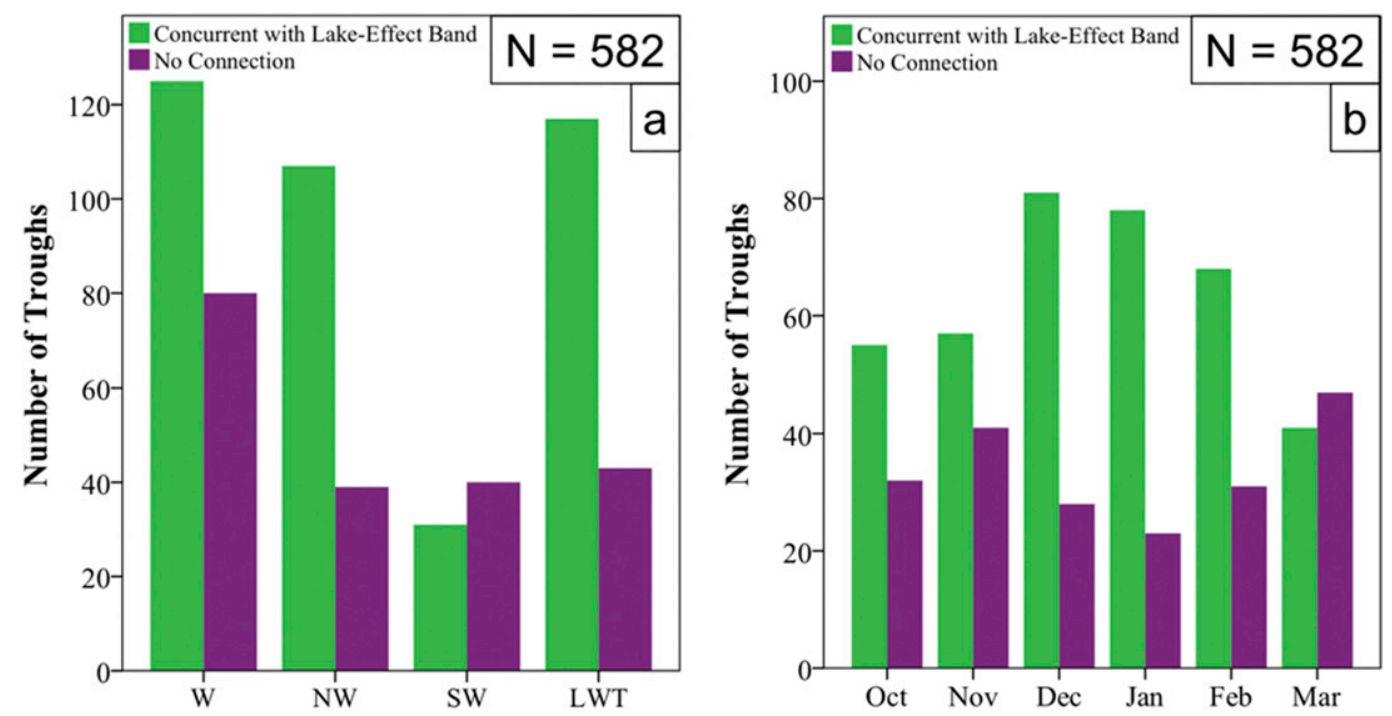

FIG. 6. (a) The number of each cold-season short-wave trough type that was both concurrent and not connected with lake-effect clouds, and (b) the number of short-wave troughs during each month that were both concurrent and not connected with lake-effect clouds.

380 troughs considered in this section were concurrent with lake-effect cloud bands on a total of 1414 lakes (an average of 3.72 Great Lakes per trough). As with the total number of short-wave troughs, the number of total Great Lakes with concurrence peaked in December and January (cf. Figs. 6b and 8).

Figure 9a shows a substantial interannual variation in the number of short-wave troughs concurrent with lake-effect cloud bands: the 2013/14 cold season featured 79, and 2009/10 featured only 39 (Fig. 9a). When examining the total number of Great Lakes that featured concurrence (recall a trough can be concurrent with a lake-effect cloud band on more than one lake), the 2013/14 cold season again had the largest number with 310, and the 2009/10 cold season only had 129 (Fig. 9b). The large number of troughs concurrent with lake-effect cloud bands during the 2013/14 cold season could indicate that short-wave troughs contributed to enhanced lake-effect snowfall for this winter (see section 4).

The frequency of how often each lake featured concurrence between lake-effect clouds and a short-wave trough was also examined. Lake Michigan had the highest number of incidences with 326 events, followed by Lake Superior with 311 events, Lake Huron with 301 events, and Lake Ontario with 275 events (Fig. 10). Lake Erie featured the fewest number of troughs concurrent with lake-effect clouds in the climatology with 201 events (Fig. 10). The number of events on each lake could be a result of many factors including size of the lake, orientation of the lake, the amount of time during which each lake is typically frozen during the cold season, and the preferred path of shortwave troughs over the Great Lakes region.

\section{Summary and discussion}

This study identified 607 short-wave troughs that crossed the Great Lakes region during the seven cold seasons spanning 2007/08 through 2013/14. December featured the most short-wave troughs of any of the cold season months (average of 15.8 each cold season). Overall, short-wave troughs had a median duration within the Great Lakes region of $24 \mathrm{~h}$. Thus, they have

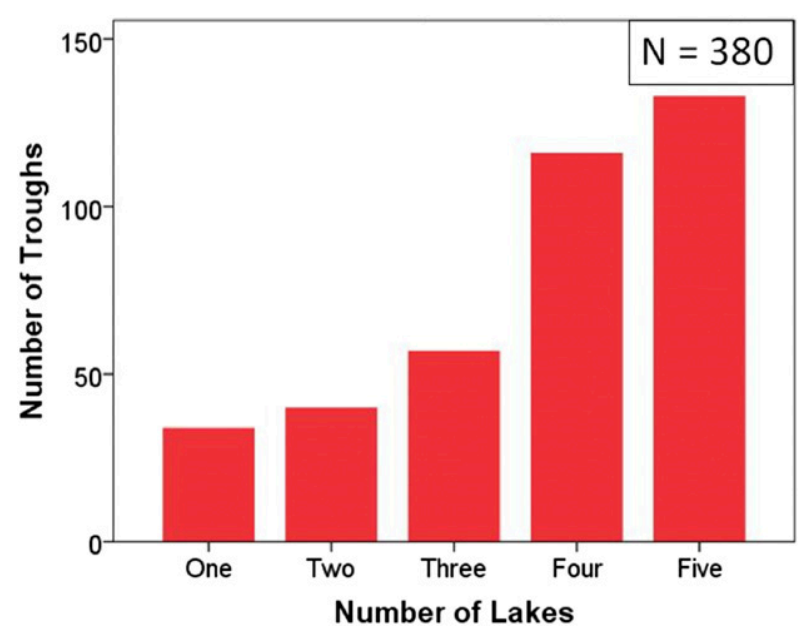

FIG. 7. The number of lakes on which a cold-season short-wave trough was concurrent with a lake-effect cloud band. 


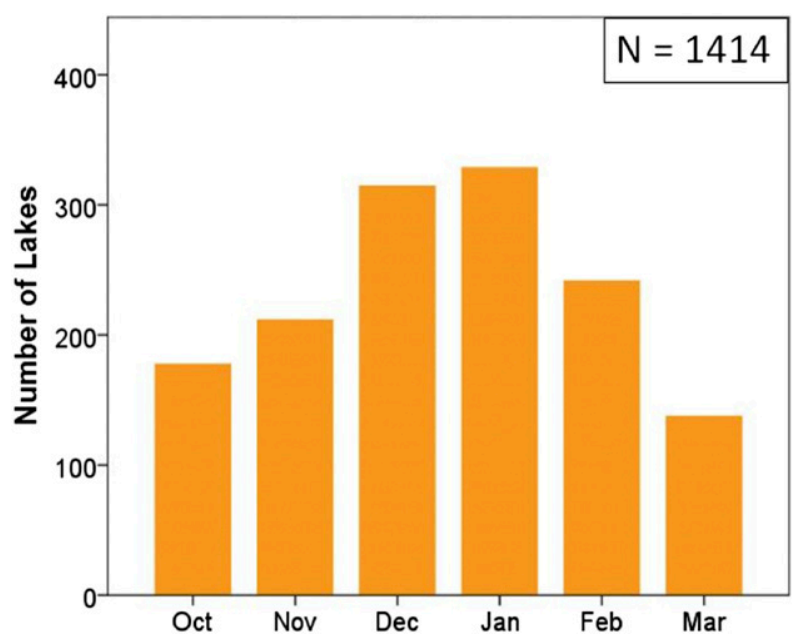

FIG. 8. Monthly distribution of the total number of times a Great Lake featured a lake-effect cloud band concurrent with a coldseason short-wave trough.

the potential to impart a substantial impact on lakeeffect precipitation (and weather in general) in the Great Lakes region.

The 2013/14 cold season had the most short-wave troughs with 116. As discussed by Jiusto et al. (1970) and Niziol et al. (1995), short-wave troughs can deepen the lake-induced boundary layer, causing increased lakeeffect snowfall. The large number of short-wave troughs during the 2013/14 cold season may have contributed to above-average-to-record snowfall across the Great Lakes region during this season. For example, over the winter (December-February) of 2013/14, Buffalo, New York received $135 \%$ of normal snowfall while Rochester, New York received 140\%, Muskegon, Michigan received $150 \%$, and Grand Rapids, Michigan received 184\% (http://www.ncdc.noaa.gov/sotc/national/201402). One possible reason for the increased number of shortwave troughs in 2013/14 stems from the winter circulation that was largely driven by blocking in the North Pacific Ocean near Alaska (Marinaro et al. 2015). This blocking led to a quasi-persistent trough that developed over the central and eastern United States. Numerous Alberta clipper systems occurred in association with this pattern and were likely associated with short-wave troughs (Marinaro et al. 2015). Further, the upper-level jet axis was often located very near to the Great Lakes region during much of the cold season (Spensberger et al. 2017) and short-wave troughs often move eastward along this waveguide.

In addition, type $\mathrm{W}$ was the most frequent classification of short-wave troughs over this 7-yr period because of the typical westerly flow across the region. Conversely, type-SW short-wave troughs occurred less than one-half as frequently as any other type of short-wave
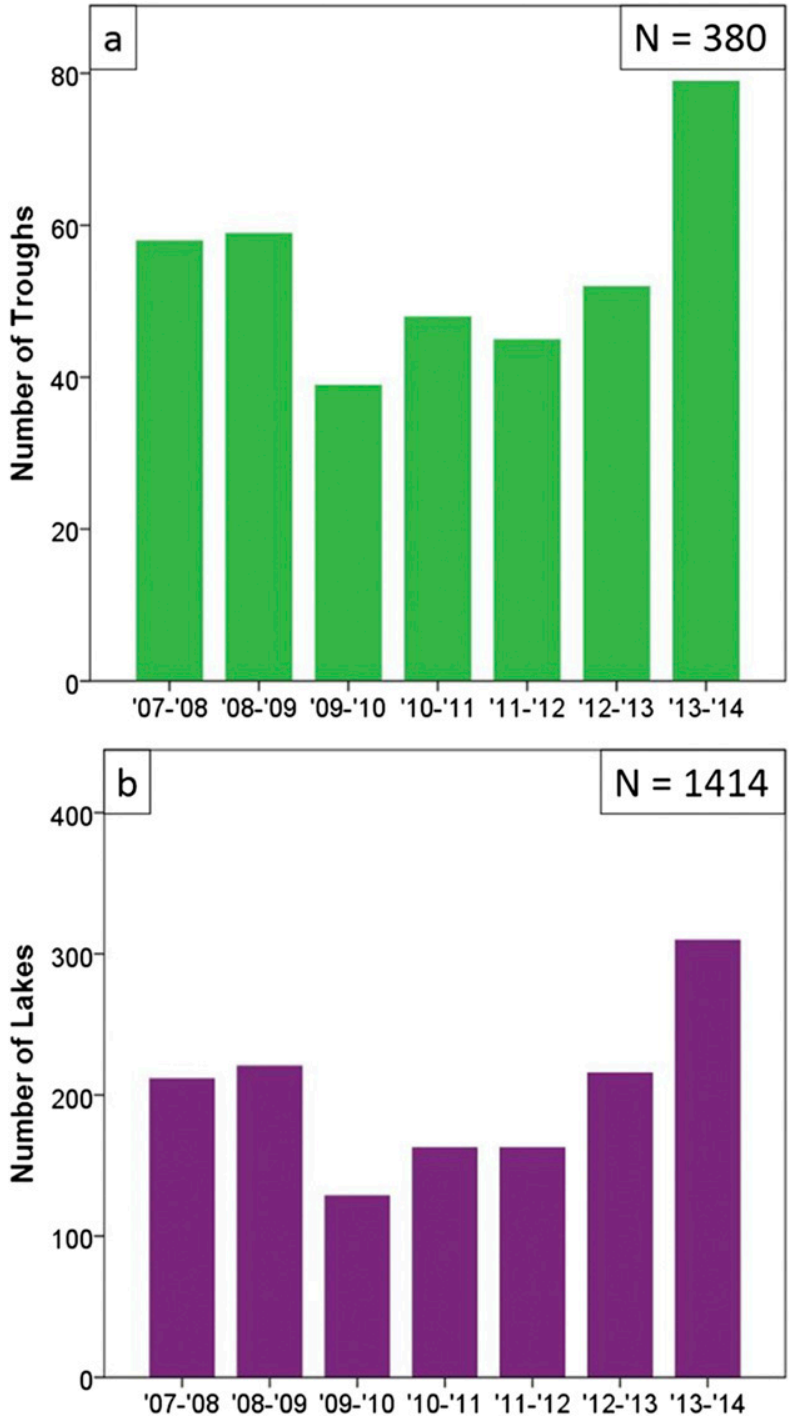

FIG. 9. (a) The number of short-wave troughs concurrent with lake-effect clouds during each cold season, and (b) the number of times that a Great Lake featured a lake-effect cloud band concurrent with a cold-season short-wave trough during each cold season.

trough (except type COL) during the 7-yr climatology. When long-wave troughs become established over the Great Lakes region, short-wave troughs have the ability to embed themselves in the mean flow and track around the base in rapid succession; 160 type-LWT short-wave troughs were identified during the climatology. An established long-wave pattern, necessary for type-LWT short waves, is likely to bring Arctic air and frequent snow to the Great Lakes region (e.g., Niziol et al. 1995). While type-COL short waves were the least frequent type near the Great Lakes region, they often spend the greatest amount of time passing through the Great Lakes region with a median duration of $54 \mathrm{~h}$. 


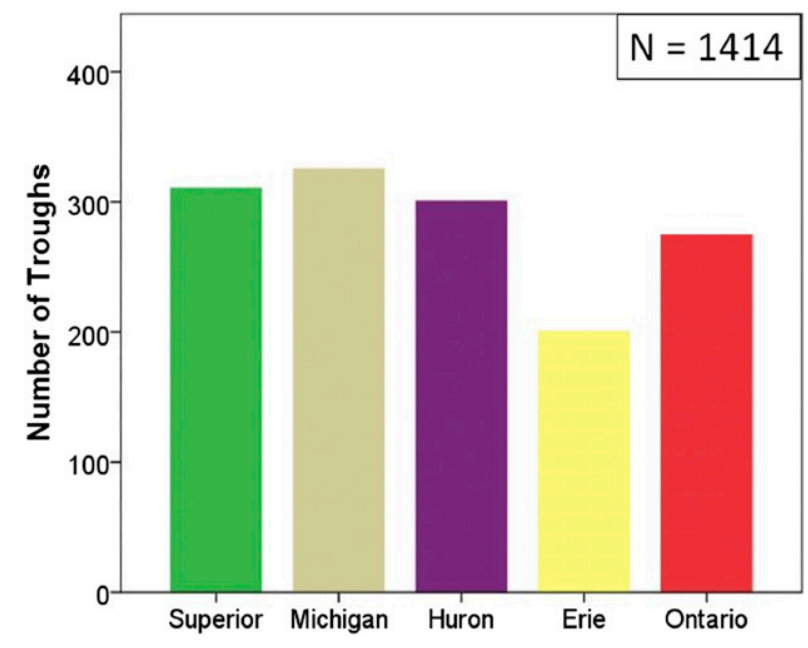

FIG. 10. The number of cold-season short-wave troughs concurrent with a lake-effect cloud band over each Great Lake.

By examining how frequently these short-wave troughs crossed a Great Lake on the same day as an observed lakeeffect cloud band, it is possible to identify the maximum potential number of climatological interactions between these troughs and lake-effect events. A majority of the short-wave troughs that passed over the Great Lakes region were concurrent with lake-effect cloud bands on at least four of the five Great Lakes, indicating the widespread impact that short-wave troughs may have on lake-effect snow. Given that all of the short-wave troughs considered in this study have at least some component of motion out of the west, it is not surprising that the north-south-oriented Lakes Michigan and Huron had a large number of concurrent events given that their length covers a substantial portion of the Great Lakes region. Further, Lake Superior is very large, allowing for a sizable number of concurrent events as well. However, Lake Ontario (surface area $\approx$ $19000 \mathrm{~km}^{2}$ ) is considerably smaller than Lake Superior (surface area $\approx 82000 \mathrm{~km}^{2}$ ) and also has an east-to-westorientation, and thus somewhat fewer concurrent events were noted as some short-wave troughs simply miss Lake Ontario to the north. Lake Erie features the same characteristics as mentioned with Lake Ontario and, given its shallow nature, often freezes in the middle of the cold season, effectively ending or substantially limiting lakeeffect cloud events. Thus, Lake Erie had the fewest number of concurrent events. Of the 161 short-wave troughs that lasted longer than $48 \mathrm{~h}$, all were concurrent with a lakeeffect cloud band on at least three Great Lakes (not shown), illustrating the potential widespread impacts these troughs might have on observed lake-effect cloud bands.

December and January had the highest number of short-wave troughs concurrent with lake-effect cloud bands over the seven cold seasons surveyed. Further, these months also contained the fewest number of short waves that had no connection with lake-effect bands. Thus, short-wave troughs are most likely (in a percentage sense) to be concurrent with lake-effect snow during December through February rather than during October, November, and March. During the transition months of the cold season temperatures are sometimes not cold enough aloft (i.e., at $850 \mathrm{hPa}$ ) for a lake to produce convection at the time a short-wave trough passes overhead.

While type-W short-wave troughs featured the most cases concurrent with a lake-effect cloud band, typeLWT short waves were found to have the second highest number of cases concurrent with lake-effect cloud bands and fewer short-wave troughs with no connection. Thus, type-LWT short-wave troughs had the highest percentage of concurrence with lake-effect cloud events. In many of these instances the long-wave trough over the Great Lakes region allowed multiple short waves to rotate through, while simultaneously bringing Arctic air into the region, allowing for prime lake-effect snow conditions (not shown). There were considerably fewer type-SW troughs in the climatology and these were much less likely to be associated with lake-effect cloudiness given that they featured a component of the upper-level flow from the southerly direction.

This study is one of the first to examine a climatology of short-wave troughs in a particular region. These troughs are important to the Great Lakes region because they are known to have a sizable impact on lakeeffect snowband intensity and position through changes in the atmospheric boundary layer stability, structure, and wind field (e.g., Jiusto et al. 1970; Niziol et al. 1995). This examination of the concurrence of lake-effect cloud bands with these short-wave troughs provides insight into just how frequently these impacts may occur during a typical cold season. In general, there are a substantial number of short-wave troughs that traverse the Great Lakes region during a typical cold season, and these troughs often pass over multiple lakes with ongoing lake-effect clouds. This research is of utility to forecasters across the Great Lakes region, given the importance of these cold-season short-wave troughs to snowfall development, evolution, and intensity. Although this work is an important step in documenting the impact of short-wave troughs on lake-effect snowbands, future work will focus, from both a climatological perspective and a case-study perspective, on the types of changes that lake-effect bands undergo as short-wave troughs pass overhead.

Acknowledgments. This research was completed as a part of the HWS Summer Research Program. The authors 
thank Dr. Neil Laird and the students who participated in the 2015 and 2016 HWS Summer Research Program for offering helpful suggestions on this work. Three anonymous reviewers provided beneficial comments and suggestions that improved the quality of this manuscript. Support for this project was provided by NSF AGS1258548 and an REU Supplement.

\section{REFERENCES}

American Meteorology Society, 2018: Short wave. Glossary of Meteorology, http://glossary.ametsoc.org/wiki/short_wave.

Baijnath-Rodino, J. A., C. R. Duguay, and E. LeDrew, 2018: Climatological trends of snowfall over the Laurentian Great Lakes basin. Int. J. Climatol., 38, 3942-3962, https://doi.org/10.1002/joc.5546.

Bates, G. T., S. W. Hostetler, and F. Giorgi, 1995: Two-year simulation of the Great Lakes region with a coupled modeling system. Mon. Wea. Rev., 123, 1505-1522, https://doi.org/10.1175/ 1520-0493(1995)123<1505:TYSOTG>2.0.CO;2.

Benjamin, S. G., and Coauthors, 2004: An hourly assimilation-forecast cycle: The RUC. Mon. Wea. Rev., 132, 495-518, https://doi.org/ 10.1175/1520-0493(2004)132<0495:AHACTR > 2.0.CO;2.

— , and Coauthors, 2016: A North American hourly assimilation and model forecast cycle: The Rapid Refresh. Mon. Wea. Rev., 144, 1669-1694, https://doi.org/10.1175/MWR-D-15-0242.1.

Call, D. A., 2005: Rethinking snowstorms as snow events: A regional case study from upstate New York. Bull. Amer. Meteor. Soc., 86, 1783-1793, https://doi.org/10.1175/BAMS-86-12-1783.

Cortinas, J., Jr., 2000: A climatology of freezing rain in the Great Lakes region of North America. Mon. Wea. Rev., 128, 35743588, https://doi.org/10.1175/1520-0493(2001)129<3574: ACOFRI $>2.0 . \mathrm{CO} ; 2$.

Harman, J. R., R. Rosen, and W. Corcoran, 1980: Winter cyclones and circulation patterns on the western Great Lakes. Phys. Geogr., 1, 28-41, https://doi.org/10.1080/02723646.1980.10642187.

Holton, J. R., and G. J. Hakim, 2013: An Introduction to Dynamic Meteorology. 5th ed. Academic Press, 532 pp.

James, E. P., and R. H. Johnson, 2010: A climatology of midlatitude mesoscale convective vortices in the rapid update cycle. Mon. Wea. Rev., 138, 1940-1956, https://doi.org/10.1175/2009MWR3208.1.

Jiusto, J. E., D. A. Paine, and M. L. Kaplan, 1970: Great Lakes snowstorms. Part 2: Synoptic and climatological aspects. State University of New York at Albany Rep. ESSA E22-49-70, 58 pp.

Kocin, P. J., P. N. Schumacher, R. F. Morales Jr., and L. W. Uccellini, 1995: Overview of the 12-14 March 1993 superstorm. Bull. Amer. Meteor. Soc., 76, 165-182, https://doi.org/10.1175/ 1520-0477(1995)076<0165:OOTMS > 2.0.CO;2.

Kristovich, D. A., and M. L. Spinar, 2005: Diurnal variations in lakeeffect precipitation near the western Great Lakes. J. Hydrometeor., 6, 210-218, https://doi.org/10.1175/JHM403.1.

— , and Coauthors, 2017: The Ontario winter lake-effect systems field campaign: Scientific and educational adventures to further our knowledge and prediction of lake-effect storms. Bull. Amer. Meteor. Soc., 98, 315-332, https://doi.org/10.1175/BAMS-D-15-00034.1.

Kumjian, M. R., and K. A. Lombardo, 2017: Insights into the evolving microphysical and kinematic structure of northeastern U.S. winter storms from dual-polarization Doppler radar. Mon. Wea. Rev., 145, 1033-1061, https://doi.org/10.1175/ MWR-D-15-0451.1.

Kunkel, K. E., N. E. Westcott, and D. A. R. Kristovich, 2002: Effects of climate change on heavy lake-effect snowstorms near
Lake Erie. J. Great Lakes Res., 28, 521-536, https://doi.org/ 10.1016/S0380-1330(02)70603-5.

Lackmann, G. M., 2001: Analysis of a surprise western New York snowstorm. Wea. Forecasting, 16, 99-116, https://doi.org/ 10.1175/1520-0434(2001)016<0099:AOASWN>2.0.CO;2.

Laird, N. F., N. D. Metz, L. Gaudet, C. Grasmick, L. Higgins, C. Loeser, and D. A. Zeilinsky, 2017: Climatology of cold season lake-effect cloud bands for the North American Great Lakes. Int. J. Climatol., 37, 2111-2121, https://doi.org/10.1002/ joc. 4838 .

Lefevre, R. J., and J. W. Nielsen-Gammon, 1995: An objective climatology of mobile troughs in the Northern Hemisphere. Tellus, 47A, 638-655, https://doi.org/10.3402/tellusa.v47i5.11558.

Marinaro, A., S. Hilberg, D. Changnon, and J. R. Angel, 2015: The North Pacific-driven severe Midwest winter of 2013/14. J. Appl. Meteor. Climatol., 54, 2141-2151, https://doi.org/10.1175/ JAMC-D-15-0084.1.

Market, P., S. Allen, R. Scofield, R. Kuligowski, and A. Gruber, 2003: Precipitation efficiency of warm-season midwestern mesoscale convective systems. Wea. Forecasting, 18, 12731285, https://doi.org/10.1175/1520-0434(2003)018<1273: PEOWMM $>2.0 . \mathrm{CO} ; 2$.

Metz, N. D., and L. F. Bosart, 2010: Derecho and MCS development, evolution, and multiscale interactions during 3-5 July 2003. Mon. Wea. Rev., 138, 3048-3070, https://doi.org/10.1175/ 2010MWR3218.1.

Niziol, T. A., W. R. Snyder, and J. S. Waldstreicher, 1995: Winter weather forecasting throughout the eastern United States. Part IV: Lake-effect snow. Wea. Forecasting, 10, 61-77, https:// doi.org/10.1175/1520-0434(1995)010<0061:WWFTTE > 2.0.CO;2.

Payer, M., N. F. Laird, R. J. Maliawco Jr., and E. G. Hoffman, 2011: Surface fronts, troughs, and baroclinic zones in the Great Lakes region. Wea. Forecasting, 26, 555-563, https://doi.org/ 10.1175/WAF-D-10-05018.1.

Petterssen, S., 1955: A general survey of factors influencing development at sea level. J. Meteor., 12, 36-42, https://doi.org/ 10.1175/1520-0469(1955)012<0036:AGSOFI > 2.0.CO;2.

_ warming of the air by the Great Lakes in winter. J. Meteor., 16, 646-652, https://doi.org/10.1175/1520-0469(1959)016<0646: OSWIDT $>2.0 . \mathrm{CO} ; 2$.

— clones. Quart. J. Roy. Meteor. Soc., 97, 457-482, https://doi.org/ 10.1002/qj.49709741407.

Sanders, F., 1988: Life history of mobile troughs in the upper westerlies. Mon. Wea. Rev., 116, 2629-2648, https://doi.org/ 10.1175/1520-0493(1988)116<2629:LHOMTI >2.0.CO;2.

Schmidlin, T. W., 1993: Impacts of severe winter weather during December 1989 in the Lake Erie snowbelt. J. Climate, 6 , 759-767, https://doi.org/10.1175/1520-0442(1993)006<0759: IOSWWD $>2.0 . \mathrm{CO} ; 2$.

Spensberger, C., T. Spengler, and C. Li, 2017: Upper-tropospheric jet axis detection and application to the boreal winter 2013/ 14. Mon. Wea. Rev., 145, 2363-2374, https://doi.org/10.1175/ MWR-D-16-0467.1.

Tuttle, J. D., and C. A. Davis, 2013: Modulation of the diurnal cycle of warm-season precipitation by short-wave troughs. J. Atmos. Sci., 70, 1710-1726, https://doi.org/10.1175/JAS-D-12-0181.1.

Wilks, D. S., 2006: Statistical Methods in the Atmospheric Sciences. 2nd ed. International Geophysics Series, Vol. 100, Academic Press, 648 pp.

Zar, J. H., 2009: Biostatistical Analysis. 5th ed. Prentice Hall, 944 pp. 